\title{
Persistência das PMEs brasileiras na exportação: uma análise dos fatores internos e externos de estímulo
}

\section{Persistence of Brazilian Small and Medium Enterprises: an analysis of internal and external stimullus factors}

\author{
Edmilson Milan \\ Universidade do Vale do Rio dos Sinos - UNISINOS - RS \\ edmilan11@hotmail.com \\ Marcelo Machado \\ Universidade do Vale do Rio dos Sinos - UNISINOS - RS \\ mmachado@unisinos.br
}

Submissão: $22 / 10 / 2019$

Aprovação: 14/09/2020

\section{RESUMO}

A atividade exportadora de pequenas e médias empresas (PMEs) tem sido estudada há décadas e vários fatores internos e externos de estímulo associados a esse tipo de organização foram identificados. Contudo, para PMEs de um país emergente com grande mercado interno, ainda há lacunas para se compreender melhor a persistência de PMEs na exportação. O presente artigo buscou compreender os fatores internos e externos que interferem na persistência das PMEs brasileiras nas exportações. Com base em 14 PMEs gaúchas que exportaram ininterruptamente de 2003 a 2017, foi realizada uma pesquisa com o método QCA para conhecer as principais combinações de fatores internos e externos presentes na persistência exportadora. Os resultados revelaram que os fatores internos presentes na persistência de PMEs exportadoras provêm da combinação dos recursos humanos, dos ganhos financeiros da exportação, da existência de inovação e de competências de marketing. Desse modo, entende-se que investimentos na capacitação de pessoas e em inovação poderiam contribuir com a permanência de PMEs exportando. Já os fatores externos presentes surgiram da combinação de condições do mercado externo, do apoio do governo, da competição e das demandas dos clientes. Destaca-se aqui o espaço para policymakers brasileiros desenvolverem instrumentos de apoio voltados aos fatores internos apontados nas PMEs. Um fator interno identificado no estudo, mas não na literatura, foi o planejamento estratégico prévio para a exportação. Assim, uma ação gerencial relevante para PMEs que buscam a persistência na atividade exportadora é a inclusão da exportação como tema estratégico anual e a sua constante revisão e destinação de orçamento.

Palavras-chave: Internacionalização de PMEs. Exportações brasileiras. Persistência na exportação.

\begin{abstract}
The export activity of small and medium-sized enterprises (SMEs) has been studied for decades and several internal and external stimulus factors associated with this type of
\end{abstract}


organization have been identified. However, for SMEs in an emerging country with a large domestic market, there are still gaps to better understand the persistence of SMEs in exports. This article sought to understand the internal and external factors that interfere with the persistence of Brazilian SMEs in exports. Based on 14 SMEs from the state of Rio Grande do Sul that exported uninterruptedly from 2003 to 2017, a survey was carried out using the QCA method to find out the main combinations of internal and external factors present in the export persistence. The results revealed that the internal factors present in the persistence of exporting SMEs come from the combination of human resources, financial gains from exports, the existence of innovation and marketing skills. Thus, it is understood that investments in training people and in innovation could contribute to the permanence of SMEs exporting. The external factors present arose from the combination of conditions in the foreign market, government support, competition and customer demands. The space for Brazilian policymakers to develop support instruments aimed at internal factors pointed out in SMEs is highlighted. An internal factor identified in the study, but not in the literature, was the prior strategic planning for export. Thus, a relevant management action for SMEs that seek persistence in the export activity is the inclusion of exports as an annual strategic theme and its constant review and budget allocation.

Keywords: Internationalization of SMEs. Brazilian exports. Persistence in exports.

\section{Introdução}

A atividade exportadora é considerada uma válvula propulsora para o desenvolvimento econômico e social de um país. As exportações proporcionam divisas que possibilitam o pagamento das necessárias compras externas, geram empregos e incremento da renda para os trabalhadores, promovem uma melhor competição entre as empresas, melhoram a qualidade e a inovação dos produtos, entre tantos outros fatores de prosperidade econômica (ARTEAGA-ORTIZ et al., 2010; LEONIDOU et al., 2007; NARAYANAN, 2015).

O Brasil ainda apresenta uma participação modesta no comércio internacional, ocupando somente a vigésima sexta posição entre os países exportadores de mercadorias no ranking da Organização Mundial do Comércio (OMC), representando cerca de 1,2\% do total exportado globalmente em 2018 (OMC - World Trade Organization Statistical Review, 2019). O comércio exterior brasileiro também se caracteriza pela concentração em grandes empresas exportadoras. Em 2017, 94\% do total exportado pelo Brasil foi realizado por grandes empresas, notadamente exportações de produtos básicos, tais como commodities primárias agrícolas e minerais (Ministério da Indústria, Comércio Exterior e Serviços MDIC, 2018).

No entanto, as PMEs são conhecidas por serem importantes geradoras de empregos, sendo responsáveis por pelo menos $60 \%$ dos empregos no setor privado mundial (AYYAGARI et al., 2011; PAUL et al., 2017; TAN et al., 2018). Assim, as exportações podem apresentar importantes vantagens para as PMEs. As vendas externas proporcionam incrementar o faturamento, melhorar a rentabilidade dos produtos, diversificar os mercados de atuação, melhorar a produtividade e a qualidade dos produtos e aumentar a competitividade geral das PMEs (GJEKANOVIKJ et al., 2015; WILLIAMS, 2008).

A atividade exportadora é motivada por fatores de estímulos internos relacionados às PMEs, tais como a disponibilidade de um produto inovador, capacidade produtiva diferenciada e, principalmente, o compromisso e o envolvimento dos administradores com as exportações, no sentido de compreender as vendas externas como fator potencial para o crescimento das empresas (Chandra et al., 2020; MOEN et al., 2016). Na mesma direção, 
fatores externos decorrentes do mercado onde as PMEs atuam também são importantes impulsionadores da atividade exportadora. A redução da dependência do mercado doméstico, a ocorrência de taxas de câmbio positivas às exportações e as decisões favoráveis de governos estrangeiros são exemplos de fatores externos de estímulos às exportações. (LEONIDOU et al., 2007; FRANCIONI et al., 2016)

Leonidou et al. (2011) mencionam que a exportação é tradicionalmente a forma mais popular de entrada em mercados internacionais, principalmente porque requer poucos recursos e envolve riscos mais baixos se comparados a outras formas mais complexas de internacionalização existentes. A falta de compromisso exportador por parte dos administradores é provavelmente o principal entrave interno determinante para a continuidade do processo de internacionalização de uma PME (NAVARRO-GARCIA et al., 2017; PAUL et al., 2017).

A atividade exportadora tem sido estudada há anos, quando relacionada aos fatores de estímulos às exportações (LEONIDOU et al., 2007; WILLIAMS, 2008; FRANCIONI et al., 2016). Entretanto, foi identificada uma lacuna teórica quanto aos fatores de estímulos, internos e externos, que participam da atividade exportadora persistente, ou seja, aqueles fatores que contibuem para que uma PME persista com suas exportações (GUNARATNE, 2014; MESCHI et al., 2017; VAILLANT et al., 2018). Dessa forma, o presente estudo procurou investigar os fatores internos e externos que interferem na persistência das PMEs gaúchas na atividade exportadora. O contexto pesquisado foram 14 PMEs gaúchas da indústria de transformação, que mantiveram exportações ininterruptas no período de 2003 a 2017, de acordo com dados do MDIC, usando a abordagem metodológica mista quali-quanti da análise qualitativa comparativa (QCA).

\section{Revisão de Literatura}

Nesta seção são apresentadas as principais abordagens teóricas que sustentaram a pesquisa. Foram considerados os estudos seminais e contemporâneos que auxiliam no entendimento dos fatores de estímulos às exportações das PMEs.

\subsection{Fatores de estímulo às exportações}

O engajamento de uma empresa na atividade exportadora é o resultado de um conjunto de estímulos internos e externos. Os estímulos internos são associados a fatores endógenos à empresa, tais como ambição de crescimento corporativo, disponibilidade de produto competitivamente diferenciado, acumulação de estoques não vendidos, enquanto os externos são derivados do ambiente onde a empresa atua ou pretende atuar, como taxa de câmbio favorável ou incentivos governamentais (LEONIDOU et al., 2007; FRANCIONI et al., 2016).

Leonidou et al. (2007) publicaram um levantamento de 32 estudos empíricos conduzidos durante o período de 1974 a 2005. Como resultado, os autores apontaram 52 estímulos que foram posteriormente refinados e consolidados em 13 direcionadores, abrangendo 40 diferentes tipos de estímulos às exportações. Ainda, os autores realizaram uma criteriosa classificação destes estímulos, de acordo com o seu impacto agregado: impacto muito alto; impacto alto; impacto moderado; baixo impacto; e muito baixo impacto.

Francioni et al. (2016) realizaram uma revisão sistemática dos principais estudos publicados sobre estímulos às exportações de PMEs. Também no sentido de atualização, Williams (2008) e Paul et al. (2017) realizaram revisões sobre os desafios das exportações de PMEs apontando que a decisão de iniciar uma atividade exportadora é induzida mais por dinâmicas internas das empresas do que por fatores externos. 


\subsubsection{Fatores internos de estímulos às exportações}

Navarro-Garcia et al. (2017) destacam que a vontade dos administradores atenua os riscos e as barreiras inerentes à exportação e aumenta a predisposição em oferecer um maior suporte e apoio aos distribuidores estrangeiros, facilitando também a adaptação do mix de marketing às necessidades dos consumidores estrangeiros e impulsionando o diferencial competitivo da empresa exportadora. Desta forma, estes autores definem o compromisso exportador como a vontade dos administradores em dedicar adequados recursos financeiros e humanos para a atividade exportadora.

Neste sentido, o compromisso gerencial para a atividade exportadora inclui a dimensão da atitude, que é a disposição favorável no sentido das exportações, e a dimensão comportamental, que se refere ao direcionamento dos esforços e recursos da empresa verdadeiramente direcionados para o suporte à atividade exportadora (MACHADO et al., 2016). Além disso, a habilidade dos gestores em assuntos relacionados às exportações, tais como conhecimento em marketing internacional, proficiência em idiomas estrangeiros e entendimento das práticas de negócios internacionais, também age como forma de estímulo às exportações (STOIAN et al., 2011).

Recentes estudos empíricos enfatizam o papel dos recursos humanos envolvidos no processo de internacionalização das empresas. As características do capital humano afetam a habilidade das PMEs na expansão de seus mercados externos. (FRANCIONI et al., 2016). Fernández-Ortiz e Lombardo (2009) evidenciam que a diversificação internacional das PMEs é positivamente relacionada aos níveis de experiências internacionais e proficiência de idiomas estrangeiros de seus gerentes. Já Francioni et al. (2016) e Lee et al. (2012) destacam a importância das redes de relacionamento para o processo de internacionalização das PMEs, mencionando que o relacionamento com clientes externos tem um papel significante em acelerar as vendas externas. Na mesma direção, Tang (2011) enfatiza que a habilidade de planejar e conduzir estrategicamente relacionamentos com parceiros-chave possibilita uma rápida internacionalização.

Também considerada como um estímulo às exportações, Leonidou et al. (2007) explicam que a estagnação ou declínio das vendas e lucros no mercado doméstico ocorre por diversos fatores: o aumento da competição, uma mudança no comportamento de consumo dos consumidores, inabilidade de lidar com problemas de marketing no mercado doméstico, etc. Para compensar esta redução nas vendas e lucros, as PMEs podem optar por entrar no mercado externo, mantendo suas operações também no mercado doméstico.

Normalmente, empresas que tratam as exportações como um meio para realizar seus objetivos adotam uma abordagem sistemática e de longo prazo no desenvolvimento de mercados externos. (WILLIAMS, 2008). No sentido financeiro, Moen et al. (2016) observam que a orientação internacional das PMEs está intimamente interrelacionada com a motivação para crescimento. Os autores reportam, ainda, que proprietários ou gerentes com forte motivação para o crescimento tendem a buscar vendas também através das exportações, bem como a apresentar crescimentos superiores em ambos os mercados, doméstico e externo.

Ayob et al. (2015) argumentam que o estabelecimento de vantagem competitiva financeira constitui uma força motivacional importante para o início ou a expansão da atividade exportadora por uma PME e que vantagens financeiras podem ser obtidas através da construção de boas relações com as instituições financeiras parceiras. Os autores explicam que PMEs utilizam esta vantagem competitiva financeira quando seus administradores entenderem que, se comparadas às operações do mercado doméstico, as operações de exportação são menos custosas e mais rentáveis.

No que tange à produção, Ganotakis e Love (2012) observam que empresas altamente produtivas muito provavelmente tornam-se exportadores, uma vez que somente aquelas com custos marginais suficientemente baixos apresentam lucros consideravelmente grandes para 
cobrir os custos fixos da entrada em mercados internacionais. A conquista de economias de escala é um importante estímulo à exportação relacionado à produção. Através das exportações, as PMEs podem diluir os custos fixos associados à administração, investimentos e outros ativos, sobre uma quantidade bem maior de produtos produzidos (LOVE; ROPER, 2015). Como resultado, o custo unitário de produção é reduzido, possibilitando as PMEs reduzir seus preços para os mercados doméstico e externo ou colher lucros maiores (LEONIDOU et al., 2007).

Neste sentido, Lu e Beamish (2001) indicam que o crescimento através da diversificação internacional é uma importante opção estratégica para as PMEs, uma vez que amplia a base de clientes e possibilita às empresas obter economias de escala e escopo. Ainda, as diferenças nas condições dos mercados internacionais permitem às PMEs tirarem proveito das imperfeições de mercado (LU; BEAMISH, 2001) e atingir maiores retornos sobre seus recursos (MOEN et al., 2016).

Por outro lado, a disponibilidade de capacidade ociosa também pode ser considerada como estímulo às exportações. Leonidou et al. (2007) explicam que algumas PMEs não utilizam toda sua capacidade de produção para pedidos relativos a clientes internos. Desta forma, esta ociosa capacidade produtiva pode ser explorada quando a produção também for direcionada para vendas externas.

No que tange à pesquisa e desenvolvimento de produtos, Leonidou et al. (2007) mencionam que o domínio de propriedade técnica de conhecimento é um importante estímulo à exportação. Estes autores discorrem que o desenvolvimento de uma especial competência tecnológica no mercado doméstico provavelmente estimulará a PME a exportar. Na mesma linha, Paul et al. (2017) afirmam que a capacidade de inovação é vital para as PMEs manterem a intensidade de suas exportações. A inovação não somente desperta e proporciona exportações, mas também modera a relação entre a produtividade e as exportações das empresas (CASSIMAN; GOLOVKO, 2011; PAUL et al., 2017).

Nesta direção, produtos únicos muito provavelmente atraem a atenção de clientes estrangeiros e criam vantagens competitivas no exterior sem requerer custos adicionais significantes. A força deste estímulo à exportação é maior quando o produto é internacionalmente patenteado, gerando constante faturamento para as PMEs por um longo período de tempo (LEE, 2012; LEONIDOU et al., 2007). Adicionalmente, Francioni et al. (2016) mencionam em seu estudo o crescente interesse das PMEs pela adoção das tecnologias da internet/web para acesso a mercados e interação com clientes estrangeiros, além de servir como forma de suporte ao crescimento internacional, tal como a coordenação das complexas atividades da cadeia de valor (GLAVAS; MATHEWS, 2014).

Quadro 1 - Fatores internos de estímulos às exportações abordados neste estudo

\begin{tabular}{|c|c|c|}
\hline Natureza & Fatores Internos & Autores \\
\hline \multirow{4}{*}{$\begin{array}{l}\text { RECURSOS } \\
\text { HUMANOS }\end{array}$} & $\begin{array}{l}\text { Compromisso exportador dos } \\
\text { administradores/empreendedores }\end{array}$ & $\begin{array}{c}\text { Gil-Barragan e Palacios-Chacon (2018); } \\
\text { Machado et al. (2016); Navarro-Garcia } \\
\text { et al. (2017) }\end{array}$ \\
\hline & $\begin{array}{l}\text { Habilidades e talentos expressados pelos } \\
\text { administradores/empreendedores }\end{array}$ & Stoian et al. (2011); Paul et al. (2017). \\
\hline & Competências dos recursos humanos & $\begin{array}{l}\text { Francioni et al. (2016); Fernández-Ortiz } \\
\text { e Lombardo (2009). }\end{array}$ \\
\hline & Rede de relacionamentos (network) & $\begin{array}{l}\text { Francioni et al. (2016); Gil-Barragan e } \\
\text { Palacios-Chacon (2018); Tang (2011). }\end{array}$ \\
\hline \multirow{3}{*}{ FINANCEIRO } & $\begin{array}{c}\text { Estagnação ou declínio nas vendas e lucros } \\
\text { do mercado doméstico }\end{array}$ & Leonidou et al. (2007). \\
\hline & $\begin{array}{l}\text { Potencial para aumentar faturamento e } \\
\text { lucros }\end{array}$ & Leonidou et al. (2007); Williams (2008). \\
\hline & Potencial para crescimento da empresa & Moen et al. (2016). \\
\hline
\end{tabular}




\begin{tabular}{|c|c|c|}
\hline & $\begin{array}{c}\text { Disponibilidade de vantagem competitiva } \\
\text { financeira }\end{array}$ & Ayob et al. (2015). \\
\hline \multirow[b]{2}{*}{ PRODUÇÃO } & $\begin{array}{l}\text { Ganhos de produtividade/economias de } \\
\text { escala }\end{array}$ & $\begin{array}{l}\text { Leonidou et al. (2007); Francioni et al. } \\
\text { (2016). }\end{array}$ \\
\hline & Disponibilidade de capacidade ociosa & $\begin{array}{l}\text { Ganotakis e Love (2012); } \\
\text { Lu e Beamish (2001); Love e Roper } \\
\text { (2015); Leonidou et al. (2007). }\end{array}$ \\
\hline \multirow{3}{*}{ INOVAÇÃO } & $\begin{array}{l}\text { Domínio de propriedade técnica de } \\
\text { conhecimento }\end{array}$ & Lee (2012); Leonidou et al. (2007). \\
\hline & Capacidade de inovação & $\begin{array}{c}\text { Paul et. al. (2017); Cassiman e Golovko } \\
\text { (2011); Love e Roper (2015). }\end{array}$ \\
\hline & $\begin{array}{l}\text { Produto com qualidade superior ou } \\
\text { característica única }\end{array}$ & Lee (2012); Leonidou et al. (2007). \\
\hline \multirow{3}{*}{ MARKETING } & $\begin{array}{c}\text { Disponibilidade de vantagens competitivas } \\
\text { de marketing }\end{array}$ & Leonidou et al. (2007); Williams (2008). \\
\hline & Utilização das ferramentas da web/internet & $\begin{array}{c}\text { Francioni et al. (2016); Glavas e } \\
\text { Mathews (2014). }\end{array}$ \\
\hline & $\begin{array}{l}\text { Capacidade de adaptação dos produtos para } \\
\text { o mercado externo }\end{array}$ & $\begin{array}{l}\text { Leonidou et al. (2007); Paul et al. } \\
\text { (2017). }\end{array}$ \\
\hline
\end{tabular}

\subsubsection{Fatores externos de estímulos às exportações}

Estudos empíricos demonstram que mercados internos recessivos ou saturados contribuem para justificar a probabilidade de exportar (FRANCIONI et al., 2016). No estudo de Leonidou et al. (2007), os autores explicam que, quando o mercado doméstico se apresenta recessivo ou saturado, as PMEs percebem que as economias de escala são difíceis de sustentar. Entretanto, Williams (2008) indica que o estímulo decorrente da saturação do mercado doméstico não é muito influente como indutor para entrada em novos mercados. $\mathrm{O}$ autor destaca que as exportações aumentam a competitividade das empresas, inclusive sua posição competitiva doméstica.

Outro importante estímulo às exportações é a necessidade de reduzir a dependência e o risco do mercado doméstico. Leonidou et al. (2007) mencionam que, operando somente no mercado interno, as PMEs colocam "todos os ovos no mesmo cesto". Chaney (2016) explica que uma característica distinta das operações de exportação, quando comparadas às do mercado doméstico, é que as transações de negócios internacionais são influenciadas pelas flutuações das taxas de câmbio das moedas. Desta forma, uma apreciação da moeda local resulta em desfavoráveis preços de venda ofertados a seus clientes no exterior, enquanto que uma depreciação da moeda local torna os preços de venda externos mais competitivos.

Em termos de oportunidades de mercado, o mercado internacional é repleto de excelentes oportunidades para PMEs, sendo que estas oportunidades, quando são mais lucrativas do que aquelas encontradas no mercado doméstico, induzem as empresas a considerar a exportação como uma estratégia atrativa (TRIMECHE, 2002). Adicionalmente, $a$ internet aumenta a possibilidade das empresas em identificar lucrativas oportunidades no exterior com baixo custo de investimentos (GLAVAS; MATHEWS, 2014).

Em seu estudo Gil-Barragan e Palacios-Chacon (2018) afirmam que decisões favoráveis de governos estrangeiros também podem ser consideradas estímulos às exportações. Muitas PMEs evitam exportar por causa da imposição de regulações severas pelos governos estrangeiros, tais como barreiras de entrada, controles de preços, restrições de quantidade, além dos impostos de importação, utilizados para proteger setores internos (LEONIDOU et al., 2007). Mansfield e Reinhardt (2008) argumentam que o estabelecimento de acordos comerciais reduz a volatilidade dos negócios internacionais, impulsionando as exportações das empresas. 
Quadro 2 - Fatores externos de estímulos às exportações abordados neste estudo

\begin{tabular}{|c|c|c|}
\hline Ambiente & Fatores Externos & Autores \\
\hline \multirow{3}{*}{$\begin{array}{l}\text { MERCADO } \\
\text { DOMÉSTICO }\end{array}$} & $\begin{array}{c}\text { Saturação ou recessão no mercado } \\
\text { doméstico }\end{array}$ & $\begin{array}{l}\text { Francioni et al. (2016); Leonidou et } \\
\text { al. (2007); Williams (2008). }\end{array}$ \\
\hline & Redução da dependência do mercado interno & Leonidou et al. (2007). \\
\hline & $\begin{array}{l}\text { Taxas de câmbio favoráveis no mercado } \\
\text { interno }\end{array}$ & $\begin{array}{l}\text { Chaney (2016); Leonidou et al. } \\
\text { (2007). }\end{array}$ \\
\hline \multirow{3}{*}{$\begin{array}{l}\text { MERCADOS } \\
\text { EXTERNOS }\end{array}$} & Taxas de câmbio favoráveis no exterior & $\begin{array}{l}\text { Chaney (2016); Leonidou et al. } \\
\text { (2007). }\end{array}$ \\
\hline & $\begin{array}{c}\text { Decisões favoráveis de governos } \\
\text { estrangeiros }\end{array}$ & $\begin{array}{l}\text { Gil-Barragan e Palacios-Chacon } \\
\text { (2018); Leonidou et al. (2007). }\end{array}$ \\
\hline & $\begin{array}{l}\text { Identificação de melhores oportunidades no } \\
\text { exterior }\end{array}$ & $\begin{array}{l}\text { Glavas e Mathews (2014); Trimeche } \\
\text { (2002). }\end{array}$ \\
\hline \multirow{3}{*}{$\begin{array}{l}\text { GOVERNO } \\
\text { DOMÉSTICO }\end{array}$} & Estímulos das agências governamentais & Leonidou et al (2011) \\
\hline & Existência de acordos comerciais & Mansfield e Reinhardt (2008). \\
\hline & Incentivo e apoio das entidades de classe & Leonidou et al. (2007) \\
\hline COMPETIÇÃO & $\begin{array}{c}\text { Ganhos de experiência internacional } \\
\text { Melhoria da competitividade doméstica }\end{array}$ & $\begin{array}{l}\text { Sullivan e Bauerschmidt (1990); Lu } \\
\text { e Beamish (2001). }\end{array}$ \\
\hline \multirow{2}{*}{ CLIENTES } & $\begin{array}{l}\text { Recebimento de ordens após a participação } \\
\text { em feiras internacionais }\end{array}$ & Leonidou et al. (2007). \\
\hline & $\begin{array}{l}\text { Recebimento de pedidos espontâneos de } \\
\text { compras do exterior }\end{array}$ & $\begin{array}{l}\text { Stoian et al. (2011), Leonidou et al. } \\
\text { (2007) }\end{array}$ \\
\hline
\end{tabular}

Leonidou et al. (2011) afirmam que os programas nacionais de apoio às exportações auxiliam empresas domésticas a realizarem suas exportações, auxiliando-as a vencer as diversas barreiras às exportações existentes. Neste sentido, Leonidou et al. (2007) explicam que as associações de indústria e de comércio, tais quais câmaras de comércio, têm um papel influente no que tange à decisão de exportar das PMEs. Ainda, competindo em diferentes e complexos mercados estrangeiros, as PMEs podem aprender sobre novas práticas de negócios, desenvolver ideias de novos produtos e ter acesso a novas fontes de recursos e capacidades. Portanto, se apropriadamente conduzidas, as exportações proporcionam uma valiosa vantagem competitiva que pode beneficiar as operações das empresas, tanto em mercados internacionais como no mercado doméstico (SULLIVAN; BAUERSCHMIDT, 1990; LU; BEAMISH, 2001).

Estudos empíricos apontam que o recebimento de pedidos espontâneos de compras do exterior como um fator importante de estímulo às exportações (STOIAN et al., 2011), mas há pedidos que provém da participação em feiras internacionais, o que demonstra o comportamento pró-ativo da empresa. Assim, uma empresa também explora a possibilidade de exportação através do investimento em feiras internacionais (LEONIDOU et al., 2007).

\section{Método}

Considerando o problema norteador da pesquisa neste estudo, de investigar os fatores internos e externos que interferem na persistência das PMEs gaúchas na atividade exportadora, foi realizada uma pesquisa de natureza mista, quantitativa e qualitativa, de nível exploratório e descritivo. Neste sentido, a estratégia adotada para o alcance do objetivo proposto neste estudo foi o método da análise qualitativa comparativa (Qualitative Comparative Analysis - QCA). A metodologia QCA é fundamentada na teoria de conjuntos e em operações da álgebra booleana (BETARELLI JUNIOR; FERREIRA, 2018) que, dadas as variáveis, podem assumir um número finito de valores entre 0 e 1 (RAGIN, 2008). Uma das contribuições do QCA é identificar situações onde exista causalidade complexa ou 
causalidade conjuntural múltipla, considerando que cada caso individual é uma combinação complexa de propriedades, um todo específico que não pode ser perdido em desmembramentos de variáveis (RIHOUX; RAGIN, 2009). Estas situações ocorrem na trajetória das PMEs gaúchas, onde se identificam determinadas PMEs que persistem nas exportações, motivadas por fatores de estímulos internos e externos, ou seja, apresentando causalidade complexa ou conjuntural múltipla que recomenda o uso do método QCA.

O método QCA não considera que as relações sejam lineares, ou seja, um fator não tem o mesmo efeito incremental entre casos para a ocorrência de um fenômeno. Segundo Rihoux e Ragin (2009), o método QCA é uma técnica que pode ser utilizada quando há a premissa da equifinalidade, ou seja, quando há casos onde diferentes combinações de fatores podem gerar o mesmo fenômeno. Assim, a combinação de condições é suficiente mas não necessária à existência de um fenômeno. O QCA foi desenvolvido para ser aplicado em uma quantidade pequena de observações e para fornecer uma abordagem macro comparativa, sendo adequado para estudos que envolvam entre três a 250 casos (Ragin, 2008).

Neste estudo, foi utilizada a técnica de conjuntos crisp (crisp set - csQCA) para a aplicação do método, pelo fato de ser a variante originalmente desenvolvida quando da criação do método QCA e também por ser a variante mais apropriada em estudos com pequeno número de casos (SANDES-FREITAS; BIZZARRO-NETO, 2015). As variáveis foram transformadas em unidades dicotômicas que indicaram sua presença (1) ou sua ausência (0) a um conjunto, conforme as proposições da álgebra booleana. Foi utilizada a versão $f_{s} Q C A 3.0$ que permite a utilização da técnica csQCA, obtida a partir do sítio eletrônico www.compasss.org. A solução intermediária, que inclui somente os casos que permanecem após a análise contrafactual, foi considerada a melhor em termos substantivos e teóricos (RAGIN, 2008) e utilizada nesta pesquisa.

Compuseram o público-alvo as PMEs gaúchas da indústria de transformação e que exportaram ininterruptamente entre os anos de 2003 a 2017. Para a definição de PME, utilizou-se o critério do número de empregados para a indústria, adotado pelo Serviço Brasileiro de Apoio às Micro e Pequenas Empresas (SEBRAE, 2018). Na indústria, consideram-se PMEs estabelecimentos que possuem entre 20 a 499 empregados. No intuito de identificar quais PMEs gaúchas do setor da indústria permaneceram exportando ininterruptamente entre os anos de 2003 a 2017, foram utilizados os dados disponíveis no sítio do MDIC/SECEX na internet. Foi gerada uma lista com 665 PMEs gaúchas que mantiveram atividade exportadora entre os anos de 2003 a 2017 e, na sequência, foram excluídas aquelas não classificadas como indústria da transformação. Após esta etapa, restaram 577 empresas.

Com base nesta lista de empresas, procurou-se identificar as empresas que estariam dispostas a participar da pesquisa. Foram contatadas diversas empresas, das quais várias não tiveram interesse ou disponibilidade para participar da pesquisa. Ao final da etapa, 14 empresas concordaram em participar do estudo. Estudos com pequeno número de casos são apontados como mais apropriados para a aplicação da variante csQCA no método QCA (SANDES-FREITAS; BIZZARRO-NETO, 2015).

Quadro 3 - Caracterização dos gestores e PMEs estudadas

\begin{tabular}{|c|c|c|c|c|c|c|c|}
\hline Empresa & Cargo & $\begin{array}{c}\text { Tempo } \\
\text { empresa }\end{array}$ & $\begin{array}{c}\text { Grau de } \\
\text { Instrução }\end{array}$ & $\begin{array}{c}\text { Código } \\
\text { entrev. }\end{array}$ & $\begin{array}{c}\text { No. } \\
\text { colab. }\end{array}$ & $\begin{array}{c}\text { Fat. } \\
\text { expo. }\end{array}$ & $\begin{array}{c}\text { Setor } \\
\text { indústrial }\end{array}$ \\
\hline Bia Brazil & $\begin{array}{c}\text { Diretora- } \\
\text { Presidente }\end{array}$ & 24 & Superior & DPBB & 38 & $90 \%$ & Têxtil \\
\hline Empre 2 & $\begin{array}{c}\text { Gerente } \\
\text { Comercial }\end{array}$ & 13 & Pós-graduado & GCE2 & 350 & $25 \%$ & Embalagens \\
\hline Xalingo & $\begin{array}{c}\text { Supervisor } \\
\text { COMEX }\end{array}$ & 02 & Superior & SCXA & 390 & $3 \%$ & Brinquedos \\
\hline Matrizaria & Diretor & 20 & Superior & DIMP & 71 & $80 \%$ & Matrizes para \\
\hline
\end{tabular}




\begin{tabular}{|c|c|c|c|c|c|c|c|}
\hline Polako & & & incompleto & & & & calçados \\
\hline Empre 5 & $\begin{array}{c}\text { Diretor } \\
\text { Comercial }\end{array}$ & 27 & $\begin{array}{c}\text { Superior } \\
\text { incompleto }\end{array}$ & DCE5 & 80 & $17 \%$ & $\begin{array}{l}\text { Componentes } \\
\text { para calçados }\end{array}$ \\
\hline JGB & $\begin{array}{l}\text { Gerente de } \\
\text { Vendas }\end{array}$ & 05 & Pós-graduado & GMVJ & 150 & $5 \%$ & $\begin{array}{c}\text { Equipamentos } \\
\text { de proteção }\end{array}$ \\
\hline Empre 7 & $\begin{array}{c}\text { Gerente } \\
\text { Comercial }\end{array}$ & 23 & Superior & GCE7 & 370 & $84 \%$ & Móveis \\
\hline Empre 8 & $\begin{array}{c}\text { Diretor } \\
\text { Comercial }\end{array}$ & 10 & Pós-graduado & DCE8 & 125 & $3 \%$ & Vinhos \\
\hline Gpaniz & $\begin{array}{c}\text { Gerente } \\
\text { Financeiro }\end{array}$ & 21 & Superior & GFGP & 230 & $8 \%$ & $\begin{array}{l}\text { Máquinas e } \\
\text { equipamentos }\end{array}$ \\
\hline $\begin{array}{c}\text { Couros } \\
\text { Krumenauer }\end{array}$ & $\begin{array}{c}\text { Diretor } \\
\text { Financeiro }\end{array}$ & 48 & Superior & DFCK & 125 & $95 \%$ & Coureiro \\
\hline $\begin{array}{c}\text { Calçados } \\
\text { Hoffles }\end{array}$ & $\begin{array}{c}\text { Diretor- } \\
\text { Presidente }\end{array}$ & 19 & Pós-graduado & $\mathrm{DPCH}$ & 146 & $20 \%$ & Calçadista \\
\hline $\begin{array}{c}\text { E.R. } \\
\text { Amantino }\end{array}$ & $\begin{array}{l}\text { Gerente de } \\
\text { Exportação }\end{array}$ & 40 & Pós-graduado & GEIB & 390 & $90 \%$ & Armas \\
\hline Empre 13 & $\begin{array}{c}\text { Gerente } \\
\text { Administrativo }\end{array}$ & 07 & Pós-graduado & GF13 & 340 & $1 \%$ & Alimentos \\
\hline $\begin{array}{c}\text { Jimo } \\
\text { Química }\end{array}$ & Diretor & 09 & Pós-graduado & DJIM & 95 & $7,5 \%$ & Químico \\
\hline
\end{tabular}

O Quadro 3 apresenta, de forma consolidada, os cargos, nível de formação e tempo de empresa dos administradores entrevistados, bem como dados sobre as PMEs gaúchas que participaram da pesquisa. Nos casos em que o pesquisador não recebeu autorização para divulgar o nome da empresa, o termo "Empre", seguido de um número que indica a ordem cronológica na qual a empresa participou da pesquisa, foi utilizado.

Para a definição dos construtos e das variáveis referentes aos estímulos às exportações, este estudo baseou-se no esquema definido por Leonidou et al. (2007), por abranger uma gama diversificada dos fatores de estímulos às exportações, tanto internos como externos. Os estudos de Willians (2008) e Francioni et al. (2016) também utilizaram o esquema de Leonidou et al. (2007) como base em suas pesquisas. Todos os fatores de estímulos às exportações indicados no estudo de Leonidou et al. (2007) foram abordados e, adicionalmente, outros fatores de estímulos às exportações foram incorporados, considerando as peculiaridades de países emergentes e as sugestões oriundas da etapa de validação dos instrumentos. A validação do instrumento de coleta foi conduzida por meio de um júri acadêmico composto por dois notórios pesquisadores brasileiros sobre internacionalização de empresas manifestaram suas opiniões. Já o júri prático foi conduzido com o Gerente de Comércio Exterior e de Relações Internacionais da Federação das Indústrias do Rio Grande do Sul (FIERGS), com mais de 20 anos de experiência na área, fez suas considerações.

Após a etapa do júri, a pesquisa teve sequência com a aplicação do questionário que, com perguntas fechadas, visou identificar a ocorrência ou a não ocorrência das variáveis que interferem como fatores internos e externos de estímulos às exportações. O questionário foi composto por questões objetivas cujas respostas foram baseadas na escala Likert, com pontuação variando de 1 a 5. Conforme Ragin (2008), para a utilização do método QCA, considera-se o pressuposto da lógica binária na abordagem csQCA, com valor 0 (zero), indicando ausência, ou 1 (um), indicando presença. Para atender a esse pressuposto, considerou-se concordo parcialmente ou totalmente (4 e 5) como condição presente (1) e discordo parcialmente ou totalmente (1 e 2) como condição ausente (0), tendo sido eliminada a opção indiferente (3). O estudo de Mello (2017) também utilizou a escala Likert para aplicar a metodologia QCA.

As entrevistas foram realizadas no período de outubro a novembro de 2018 nas 14 PMEs gaúchas identificadas, indicadas no Quadro 3. Quando das aplicações do questionário, 
enquanto as questões eram respondidas, os entrevistados explicavam os fatores de estímulos às exportações que mais se destacam na atividade exportadora de suas empresas. Esses relatos foram explorados e registrados pelos pesquisadores, o que reflete uma das vantagens do QCA.

Para o QCA, é preciso construir a Tabela Verdade (Truth Table), representada por meio das informações binárias colhidas. Na medida em que se progredia com a elaboração da planilha eletrônica, procedeu-se à análise dos dados quantitativos para cada variável. Nesta etapa, quando as respostas oriundas do questionário não confirmavam a presença ou a ausência de determinada variável, novos contatos com os entrevistados foram realizados, visando dirimir dúvidas. Juntamente com o método QCA, fez-se a análise de conteúdo quando das entrevistas.

$\mathrm{Na}$ etapa de preparação do material a ser analisado, realizou-se o processo de codificação, isto é, a separação dos dados em pequenas categorias de informação, buscandose evidências a partir dos dados coletados, atribuindo-lhes um rótulo (BAILEY, 1994). Nesta pesquisa, as categorias de análise empregadas na análise de conteúdo seguiram a mesma denominação utilizada para as variáveis indicadas nos Quadros 1 e 2. Entretanto, uma categoria adicional surgiu da análise do conteúdo, identificada como uma categoria emergente, que foi identificada neste estudo como "planejamento estratégico".

\section{Análise dos Resultados}

Nesta seção são apresentados e analisados os resultados observados na pesquisa, tanto aqueles decorrentes da utilização do método QCA, como os resultados dos dados qualitativos obtidas oriundos das entrevistas realizadas nas empresas participantes.

\subsection{Fatores internos de estímulos às exportações}

Buscou-se, primeiro, compreender como os elementos internos relacionados às PMEs auxiliaram como fatores de estímulos à atividade exportadora, considerando as variáveis denominadas como recursos humanos, financeiro, produção, inovação e marketing. O Quadro 04 apresenta os resultados consolidados de cada variável, no que se refere à presença ou à ausência dos fatores internos de estímulos às exportações considerados neste estudo.

Quadro 04 - Fatores internos de estímulos às exportações

\begin{tabular}{|c|c|c|}
\hline Variável (Fator) & Casos Presentes & Casos Ausentes \\
\hline Recursos Humanos & 12 & 02 \\
\hline Financeiro & 12 & 02 \\
\hline Produção & 09 & 05 \\
\hline Inovação & 13 & 01 \\
\hline Marketing & 11 & 03 \\
\hline
\end{tabular}

O resultado apresentado por meio da solução do fsQCA (Quadro 05) indica que a combinação das variáveis recursos humanos, financeiro, inovação e marketing estão presentes em 73,3\% dos casos para o construto fatores internos de estímulos às exportações. O quadro também demonstra que a combinação da presença das variáveis recursos humanos, financeiros e inovação, com a ausência da variável produção, representa $26,7 \%$ dos casos estudados para o construto fatores internos de estímulos às exportações.

Quadro 5 - Combinações do fsQCA para fatores internos

\begin{tabular}{|c|c|c|}
\hline Variáveis & Casos & Consistência \\
\hline RH*FINAN*INOVA*MKT & $73,3 \%$ & $100 \%$ \\
\hline RH*FINAN*PRODU*INOVA & $26,7 \%$ & $100 \%$ \\
\hline
\end{tabular}


Os resultados demonstraram que o desenvolvimento da atividade exportadora de uma PME está relacionado à prévia decisão de exportar, através de um processo planejado e sistemático (WILLIAMS, 2008), e diretamente conectado à disponibilização de vantagens competitivas atreladas a fatores internos motivacionais (LEONIDOU et al., 2007). Neste sentido, o diretor DIMP explica a importância do planejamento para o desenvolvimento das exportações, em consonância como o estudo de Williams (2008): "Na exportação, tudo começa com o planejamento. As exportações precisam estar no planejamento estratégico da empresa, indicando o percentual do faturamento que a empresa pretende atingir com as exportações e os recursos necessários".

A decisão de formalizar a atividade exportadora no planejamento de uma PME, entretanto, decorre principalmente da orientação internacional dos administradores que, como fator de estímulos às exportações, ficou evidenciada neste estudo: doze das quatorze empresas que participaram desta pesquisa indicaram presença de proatividade e compromisso por parte dos administradores com as exportações.

Destaca-se a fala de DPBB, fundadora e diretora-presidente da empresa Bia Brazil, que exporta desde 1996 e está presente em mais de 60 países: "[...] com as exportações a gente tem um incentivo, pequeno, mas tem, de impostos para que consiga exportar. E isso me levou a pensar que eu não posso ter um negócio só no Brasil [...]". Navarro-Garcia et al. (2017) destacam que o compromisso dos administradores com as exportações reduz os riscos e as barreiras vivenciadas pelas PMEs em suas atividades exportadoras. Na mesma direção, Machado et al. (2016) indicam que um maior direcionamento de recursos à atividade exportadora tem impactos positivos na performance dos mercados externos das empresas.

Neste estudo, as PMEs que possuem um percentual considerável de seu faturamento oriundo das exportações ou que evidentemente estão motivadas em ampliar suas exportações são aquelas que consideram a atividade exportadora como um fator potencial para o desenvolvimento e crescimento da empresa. Este resultado está em conformidade com o estudo de Moen et al. (2016) que indica que a orientação internacional das PMEs está diretamente interrelacionada com a motivação do crescimento.

A gerente GMVJ da empresa JGB, cujas exportações representam atualmente aproximadamente $5 \%$ de seu faturamento, relatou a importância da atividade exportadora como fator para crescimento do tamanho de sua empresa, que pretende aumentar suas vendas também por meio das exportações, tendo projetado que, nos próximos anos, $15 \%$ das vendas anuais sejam provenientes da comercialização em mercados estrangeiros.

A estagnação ou declínio nas vendas e lucros no mercado doméstico, como fator de estímulo às exportações, não apresentou relevância nos casos estudados neste trabalho: somente sete das quatorze empresas entrevistadas afirmaram presença deste fator como estímulo às suas exportações. $\mathrm{O}$ fato das PMEs estudadas terem exportado ininterruptamente, entre os anos de 2003 a 2017, pode ter proporcionado o contínuo desenvolvimento de uma cultura exportadora nestas empresas, que direcionam parte de sua produção ao exterior independentemente das condições de vendas do mercado interno.

Mesmo que não tenha constado como fator presente das principais combinações dos fatores internos de estímulos às exportações apuradas pelo método QCA, demonstradas no Quadro 05, a produção normalmente é considerado um importante fator de estímulo às exportações, em consonância com o estudo de Love e Roper (2015), quando afirmam que a exportação torna a PME mais produtiva, proporcionando economias de escala.

$\mathrm{O}$ fato das PMEs que participaram desta pesquisa terem direcionado parte de sua produção anual ao exterior, no período considerado neste estudo, decorrente de um planejamento prévio, com o direcionamento de recursos necessários e tempestivos à produção dos bens exportáveis, provavelmente explica a não percepção da produção como fator motivador de suas exportações. 
No que tange a economias de escala, a sazonalidade do mercado interno no setor de calçados, decorrente das estações do ano, proporcionou à empresa Hoffles produzir uma quantidade superior àquela demandada pelo mercado doméstico, sendo a produção excedente exportada para mercados externos. Nesta mesma direção, a adoção da ferramenta Lean Manufacturing permitiu que a empresa JGB dobrasse a produtividade de sua fábrica, possibilitando à empresa trabalhar com melhores produtos e com preços mais competitivos nos mercados externos.

Também relacionada à produção, Cassiman e Golovco (2011) mencionam a inovação como estímulo à exportação. Neste sentido, a fala de DPBB explica a importância da inovação no setor de atuação da empresa Bia Brazil: "[...]o atleta, para ser mais rápido em sua modalidade, os fabricantes precisaram fazer constantes inovações em tecidos. [...] onde tem o filtro solar, a parte do suar e absorver. [...]."

A relevância da inovação para o desenvolvimento e crescimento da atividade exportadora de uma PME apresentou importantes evidências, em conformidade com o estudo de Paul et al. (2017) que afirma que a capacidade de inovação é fundamental para que as PMEs mantenham a intensidade de suas exportações. Somente uma das quatorze PMEs que participaram desta pesquisa apresentou ausência de inovação como fator interno de estímulo às exportações. A fala da diretora-presidente DPBB exemplifica a importância da disponibilidade de produto inovador: "[...] porque a roupa era tudo igual [...] eu estava ali na feira com uma proposta de uma roupa justa que era extremamente difícil das pessoas fora do Brasil aceitarem aquilo [...] eu sei que era um produto bom, que o tecido era bom, que era coisa, mas eu precisava estar lá presente”.

Os resultados deste estudo demonstraram que as empresas entrevistadas consideram as ações de marketing como fatores internos de estímulos às exportações: onze das quatorze empresas que participaram da pesquisa indicaram presença do fator marketing como estímulo às suas exportações. As vantagens competitivas do marketing são importantes fatores internos de estímulos às exportações. (FRANCIONI et al., 2016).

Nesta direção, percebeu-se que as PMEs que participaram desta pesquisa possuem uma constante preocupação no que se refere a possuir vantagens competitivas de marketing com o intuito de satisfazer as necessidades de seus clientes de uma forma mais eficiente e efetiva que seus competidores internacionais. Embora a facilidade para adaptação das questões relacionadas ao marketing, muitas vezes necessárias para atender requisitos da legislação, necessidade dos clientes e tecnologias em mercados estrangeiros, apresenta-se como fator primordial para a conquista dos mercados internacionais, estas adaptações exigem custos extras, tempo e dedicação por parte das PMEs, em consonância com o estudo de Leonidou et al. (2007).

Entretanto, o atendimento às adaptações exigidas é um importante fator interno de estímulo à atividade exportadora das PMEs. A fala do gerente GFGP enfatiza a importância deste fator: "Cada país que operamos tem uma norma e um sistema de segurança. [...] Existe uma válvula de gás diferenciada com relação à utilizada no Brasil. [...] A adaptação do produto é essencial para realizar as vendas para clientes estrangeiros”.

Quadro 06 - Fatores internos de estímulos às exportações evidenciados na pesquisa

\begin{tabular}{|c|c|c|c|}
\hline Fatores & Descrição & Evidência das PMEs & Conexão teórica \\
\hline $\begin{array}{c}\text { Recursos } \\
\text { Humanos }\end{array}$ & $\begin{array}{c}\text { Comprometimento } \\
\text { exportador }\end{array}$ & $\begin{array}{c}\text { O compromisso com as exportações, } \\
\text { por parte dos administradores, é } \\
\text { determinante para a atividade } \\
\text { exportadora das PMEs. }\end{array}$ & $\begin{array}{c}\text { Navarro-Garcia et al. } \\
(2017) \\
\text { Machado et al. (2016) }\end{array}$ \\
\hline Ganhos & $\begin{array}{c}\text { Exportações como fator de } \\
\text { aumento } \\
\text { faturamento/lucros }\end{array}$ & $\begin{array}{c}\text { As exportações são um fator potencial } \\
\text { para crescimento do faturamento, } \\
\text { lucros e tamanho (porte) de suas }\end{array}$ & $\begin{array}{c}\text { Leonidou et al. (2007) } \\
\text { Williams (2008) } \\
\text { Moen et al. (2016) }\end{array}$ \\
\hline
\end{tabular}




\begin{tabular}{|c|c|c|c|}
\hline Financeiro & PMEs. & \\
\hline Inovação & $\begin{array}{c}\text { Produto com qualidade } \\
\text { superior ou característica } \\
\text { única }\end{array}$ & $\begin{array}{c}\text { Produto com qualidade superior ou } \\
\text { característica única é fator motivador } \\
\text { de suas exportações. }\end{array}$ & Leonidou et al. (2007) \\
\hline
\end{tabular}

Considerando os resultados da pesquisa, o Quadro 06 demonstra os fatores internos de estímulos às exportações evidenciados neste estudo. A importância dos estímulos às exportações relacionados aos fatores internos das empresas analisadas ficou bastante evidenciada nesta pesquisa, uma vez que o método QCA indicou que a combinação da presença dos fatores internos classificados como recursos humanos, financeiro, inovação e marketing ocorreu numa intensidade relevante em $73,3 \%$ dos casos estudados

\subsection{Fatores externos de estímulos às exportações}

Procurou-se, aqui, entender como os fatores externos às PMEs estimularam a atividade exportadora levando em consideração as variáveis classificadas como mercado doméstico, mercados externos, governo doméstico, competição e clientes. O Quadro 07 apresenta os resultados consolidados de cada variável, no que se refere à presença ou à ausência dos fatores externos de estímulos às exportações considerados nesta pesquisa.

Quadro 07 - Fatores externos de estímulos às exportações

\begin{tabular}{|c|c|c|}
\hline Variável (Fator) & Casos Presentes & Casos Ausentes \\
\hline Mercado Doméstico & 08 & 06 \\
\hline Mercados Externos & 11 & 03 \\
\hline Governo Doméstico & 11 & 03 \\
\hline Competição & 08 & 06 \\
\hline Clientes & 14 & 00 \\
\hline
\end{tabular}

O resultado apresentado por meio da solução fsQCA (Quadro 08) indica que a combinação das variáveis mercado externo, governo doméstico, competição e clientes estão presentes em $50 \%$ dos casos para o construto fatores externos de estímulos às exportações. $\mathrm{O}$ quadro também indica que a combinação das variáveis mercado doméstico, governo doméstico, competição e clientes estão presentes em $42,9 \%$ dos casos para o construto fatores externos de estímulos às exportações.

Quadro 08 - Combinações do fsQCA para fatores externos

\begin{tabular}{|c|c|c|}
\hline Variáveis & Casos & Consistência \\
\hline MERCEXT*GOVDOM ${ }^{*}$ COMPE*CLIENTES & $50 \%$ & $100 \%$ \\
\hline MERCDOM ${ }^{*}$ GOVDOM ${ }^{*}$ COMPE ${ }^{*}$ CLIENTES & $42,9 \%$ & $100 \%$ \\
\hline
\end{tabular}

Mesmo que a saturação ou recessão no mercado doméstico é considerada como um importante fator externo de estímulo às exportações na literatura disponível (LEONIDOU et al., 2007; FRANCIONI et al., 2016), neste estudo, entretanto, somente sete das quatorze empresas entrevistadas afirmaram presença deste fator como estímulo às suas exportações. Novamente, a continuidade da atividade exportadora das PMEs gaúchas participantes desta pesquisa pode explicar este resultado, considerando que estas PMEs persistiram com a atividade exportadora independente da situação do mercado interno.

No que tange ao fator relacionado à redução da dependência do mercado doméstico, nove de quatorze PMEs que participaram desta pesquisa indicaram presença deste fator de estímulo em suas exportações. Nesta direção, o diretor-presidente DPCH e o diretor comercial 
DCE5 citaram a importância de reduzir a dependência com relação ao mercado interno por meio das vendas externas, principalmente para se prevenir de momentos de recessão econômica do mercado brasileiro. Estes relatos estão em consonância com o estudo de Leonidou et al. (2007), que menciona que a diversificação de mercados internacionais evita que as PMEs coloquem "todos ovos no mesmo cesto".

A valorização da moeda local nos países dos clientes estrangeiros são fatores externos que estimulam as exportações em função da ótica financeira Assim, no que se refere aos mercados de câmbio no exterior, a valorização da moeda local pode agir como um estímulo às exportações das PMEs, em conformidade com o estudo de Chaney (2016). Entretanto, muitas vezes, nos períodos em que ocorre uma desvalorização da moeda brasileira, normalmente se verifica o mesmo movimento nas moedas locais dos países em desenvolvimento, fato que anula ou reduz nossa competitividade com relação às exportações brasileiras para esses países. A fala de DPBB da Bia Brazil exemplifica esta situação: "[...] a coisa está tão globalizada que se o dólar cair aqui a 2, por exemplo, vai cair no mundo também, hoje acompanha, há um tempo atrás não acompanhava, mas hoje acompanha”.

Com relação a programas governamentais de apoio às exportações, tais como apoio com treinamentos e assessoria, doze das quatorze empresas que participaram da pesquisa indicaram presença deste fator como estímulo às suas exportações. As atividades de desenvolvimento de mercados externos são uma importante forma de elaboração de programas governamentais de estímulos às exportações, conforme indicado no estudo de Gençtürk e Kotabe (2001). Neste sentido, as iniciativas realizadas pela Apex-Brasil também foram consideradas como fatores de estímulos às exportações nesta pesquisa, uma vez que onze das quatorze empresas entrevistadas indicaram a presença das ações da Apex-Brasil como fatores de estímulos às suas exportações.

Segundo relato da diretora-presidente DPBB, a Apex-Brasil tem um papel fundamental no desenvolvimento das exportações brasileiras, principalmente quando promove a participação de PMEs em feiras internacionais. Nestas ocasiões, a disponibilização da estrutura física montada nas feiras e o suporte técnico dos tradutores de idiomas, além da promoção de rodada de negócios com clientes estrangeiros, são considerados exemplos de sucesso na atuação da Apex-Brasil no que tange ao apoio às empresas exportadoras brasileiras.

A forte competição no mercado doméstico, em algumas situações, torna a exportação um caminho mais rentável, além de fortalecer a PME perante seus concorrentes locais o que auxilia a melhorar a produtividade das PMEs exportadoras (LOVE; ROPER, 2015). O diretor DFCK exemplifica esta situação: "[...] mercados externos, que requerem qualidade superior, conhecimento de negócios internacionais e boas práticas de mercado [...] as exportações tornam-se um mercado mais rentável para a nossa empresa".

Neste estudo, os resultados manifestaram que as vendas externas decorrem de uma estratégia planejada, com direcionamento proativo para identificar e conquistar clientes estrangeiros, através da participação em feiras, em missões empresariais e da contratação de representante comercial, conforme indicado no estudo de Williams (2008).

Para o desenvolvimento da atividade exportadora de uma PME, é fundamental a persistente realização de iniciativas proativas visando promover seus produtos no exterior. Nesta direção, fala a DPBB: "[...] não insistimos uma vez em feiras, insistimos dez anos na mesma feira, sendo que pessoas passavam e diziam assim, 'faz três anos que eu vejo o teu estande, hoje eu vou ver o que que tu tens' [...]".

Adicionalmente, algumas situações particulares, inerentes a determinados segmentos de mercado, exigem ações proativas das empresas para a conquista de mercados externos. Neste sentido, a gerente GEIB relata: "[...] participamos da Shot Show, feira internacional de armas, onde são encontrados todos os distribuidores. $O$ recebimento de pedidos espontâneos 
e inesperados de compra do exterior não se aplica ao nosso caso". Complementado pelo gerente GCE2, "[...] nenhuma empresa estrangeira compra embalagens sem previamente conhecer nosso produto e nossa empresa. Não há pedidos espontâneos do exterior."

Por outro lado, a ocorrência de recebimento de pedidos espontâneos e inesperados do exterior ocorre com uma frequência relevante, conforme indicado no estudo de Stoian et al. (2011). Neste trabalho, 50\% das empresas entrevistadas indicaram que realizam vendas externas decorrentes de pedidos de compras recebidos do exterior de forma inesperada. $\mathrm{O}$ relato de DPBB explica como ocorre o recebimento de pedidos espontâneos de compras do exterior: "[...] Às vezes, o comprador estrangeiro nos identifica pela internet/web; em outras situações, conhece outro cliente nosso que nos indica. Atualmente, a internet/web é uma ferramenta que muito aproxima as empresas."

O quadro 09 busca conectar os fatores externos identificados com as evidências mostradas na coleta de dados dos casos analisados e, ainda, os autores que verificaram os mesmos fatores.

Quadro 09 - Fatores externos de estímulos às exportações evidenciados no estudo

\begin{tabular}{|c|c|c|c|}
\hline Fator & Descrição & Evidência das PMEs & Conexão teórica \\
\hline $\begin{array}{c}\text { Mercados } \\
\text { Externos }\end{array}$ & $\begin{array}{c}\text { Identificação de } \\
\text { melhores oportunidades } \\
\text { no exterior }\end{array}$ & $\begin{array}{c}\text { Melhores oportunidades no exterior são } \\
\text { determinantes para a atividade } \\
\text { exportadora de suas PMEs. }\end{array}$ & $\begin{array}{c}\text { Trimeche (2002) } \\
\text { Glavas e Mathews } \\
(2014)\end{array}$ \\
\hline $\begin{array}{c}\text { Governo } \\
\text { Doméstico }\end{array}$ & $\begin{array}{c}\text { Programas de apoio às } \\
\text { exportações- assistência } \\
\text { e treinamento }\end{array}$ & $\begin{array}{c}\text { Programas governamentais de apoio às } \\
\text { exportações ajudam no } \\
\text { desenvolvimento da atividade } \\
\text { exportadora. }\end{array}$ & Leonidou et al (2011) \\
\hline Clientes & $\begin{array}{c}\text { Demandas após ações } \\
\text { pró-ativas }\end{array}$ & $\begin{array}{c}\text { Recebimento de pedidos do exterior, } \\
\text { após ações pró-ativas como a } \\
\text { participação em feiras internacionais. }\end{array}$ & Leonidou et al. (2007) \\
\hline
\end{tabular}

A maior parte da literatura sobre empreendedorismo internacional destaca que a intensidade da atividade exportadora é positivamente afetada por fatores internos, tais como estímulos por dispor de vantagens competitivas e proatividade. Entretanto, recentes estudos reabrem esta discussão, pois indicam que a combinação de fatores externos e a reatividade, como, por exemplo, o recebimento de pedidos de compras espontâneos do exterior, tem papel relevante como estímulo às exportações (GIL-BARRAGAN; PALACIOS-CHACON, 2018).

A combinação da presença dos fatores internos classificados como recursos humanos, financeiro, inovação e marketing, que ocorreu numa intensidade relevante em $73,3 \%$ dos casos estudados no método QCA, demonstrou a importância do alinhamento e diligência nas atividades internas das PMEs no que tange à persistência na atividade exportadora.

\section{Considerações finais}

Este estudo proporcionou a abordagem dos fatores internos e externos presentes na persistênca nas exportações das PMEs brasileiras. No que se referem aos fatores internos, estes conhecimentos permitem aos empreendedores e gestores, quando da formulação de estratégias de exportação, uma análise no sentido de compreenderem quais são os pontos fortes das áreas internas de suas empresas que provavelmente configuram-se como vantagens competitivas propulsoras das vendas externas.

Neste sentido, no sentido das implicações gerenciais, ficou evidenciada a importância do planejamento da atividade exportadora, categoria emergente nesta pesquisa e não identificada na literatura estudada como um fator de estímulo às exportações. A formalização do planejamento por meio de estratégias, ações e recursos para as vendas externas, além de propiciar o desenvolvimento das exportações, ratifica o envolvimento e o compromisso dos 
administradores com o tema, considerado outro relevante fator interno de estímulo para a persistência da PME nas exportações. A inovação de produtos e os ganhos de escala de produção apresentaram-se, também, como fatores positivos para vencer a forte competitividade nos mercados internacionais.

Ainda, este estudo demonstrou que a efetiva concertação das áreas internas de uma PME, além de reduzir a incidência de barreiras internas, atua como um potencial fator de estímulo às exportações. Assim, o estudo trouxe à tona a importância da combinação de elementos sob controle dos gestores - recursos humanos, inovação e competências de marketing - que estão presentes na persistência exportadora das PMEs estudadas. Esses elementos, normalmente, não são tratados em estudos de continuidade de exportação (MESCHI et al., 2017; VAILLANT et al., 2018).

Ainda no concernente à contribuição científica, o estudo contribuiu para reduzir uma lacuna teórica relacionada especificamente aos fatores internos e externos que interferem na persistência da atividade exportadora de PMEs de mercados emergentes. Desta forma, descobriu-se que fatores como a existência de um planejamento estratégico efetivo para o empreendimento internacional é um fator presente na persistência de PMEs exportadoras de mercados emergentes, ao contrário de estudos com PMEs de mercados desenvolvidos (CHANDRA et al., 2020).

Esta pesquisa também proporcionou uma visão da combinação dos fatores internos e externos de estímulos inerentes aos processos de exportação em um único estudo, temas normalmente analisados de forma isolada em outros trabalhos científicos (MORAIS; FERREIRA, 2020; PAUL et al., 2017). A apresentação consolidada numa mesma pesquisa permite às PMEs uma observação mais holística da atividade exportadora, pois demonstra não somente os motivos que proporcionam exportações, mas também os desafios intrínsecos às vendas externas que precisam ser adequadamente endereçados.

Este trabalho, contudo, possui limitações que devem ser consideradas quando da interpretação de suas contribuições. Primeiramente, trata-se de um estudo que envolveu quatorze exportadoras gaúchas, dentre centenas de empresas gaúchas que exportaram no período considerado nesta pesquisa. As contribuições são decorrentes de PMEs que representam diversos segmentos da indústria gaúcha, não sendo relacionados exclusivamente a empresas de um determinado setor industrial.

Quanto aos fatores que interferem na atividade exportadora, este estudo limitou-se aqueles que mais apareceram na literatura estudada, considerando a classificação proposta por Leonidou et al. (2007), de forma adaptada, para os fatores de estímulos às exportações, bem como aqueles fatores mais aderentes à realidade de países emergentes. Desta forma, existem outros fatores que impactam as vendas externas não abordados por esta pesquisa.

Considerando as contribuições apresentadas nesta pesquisa, bem como suas limitações, há diversas proposições que podem servir como base para futuras pesquisas. Uma abordagem promissora de pesquisa seria investigar, no mesmo período analisado, o caso de PMEs que desistiram de exportar. A comparação entre os resultados dessa pesquisa com o presente estudo abriria um espaço frutífero para o desenvolvimento de programas governamentais de apoio às exportações. Ainda, um estudo sobre a formulação e implementação do planejamento estratégico de exportações contribuiria com novas descobertas cientïficas, além de auxiliar as PMEs que pretendem iniciar sua trajetória exportadora. 


\section{REFERÊNCIAS}

ARTEAGA-ORTIZ, J.et al. Why Don't We Use the Same Export Barrier Measurement Scale? An Empirical Analysis in Small and Medium-Sized Enterprises. Journal of Small Business Management, v.48, n. 3, p. 395-420, 2010.

AYOB, A.H. et al. Financial factors and export behavior of small and medium-sized enterprises in an emerging economy. Journal of International Entrepreneurship, v.13, n. 1, p. 49-66, 2015.

AYYAGARI, M.; DEMIRGÜC-KUNT, A.; MARKSIMOVIC, V. Small vs. young firms across the world - contribution to employment, job creation, and growth. Policy Research Working Paper 5631. The World Bank Development Research Group, 2011.

BAILEY, K. D. Methods of Social Research. New York: The Free Press, 1994.

BETARELLI JUNIOR, A.A.; FERREIRA, S.F. Introdução à análise qualitativa comparativa e aos conjuntos Fuzzy (fsQCA). Brasília: Enap, 2018.

CASSIMAN, B.; GOLOVKO, E. Innovation and internationalization through exports. Journal of International Business Studies, v. 42, n.1, p. 56-75, 2011.

CHANDRA, A.; PAUL, J.; CHAVAN, M. Internationalization barriers of SMEs from developing countries: a review and research agenda. International Journal of Entrepreneurial Behavior \& Research, 2020. https:// doi 10.1108/IJEBR-03-2020-0167.

CHANEY, T. Liquidity constrained exporters. Journal of Economic Dynamics and Control, v. 72, n.1, p. 141-154, 2016.

FERNÁNDEZ-ORTIZ, R.; LOMBARDO, G.F. Influence of the capacities of top management on the internationalization of SMEs. Entrepreneurship \& Regional Development: An International Journal, v.21, n.2, p. 131-154, 2009.

FRANCIONI, B.; PAGANO, A.; CASTELLANI, D. Drivers of SMEs' exporting activity: A review and research agenda. Multinational Business Review, v. 24, n.3, p. 194-215, 2016.

GANOTAKIS, P.; LOVE, J.H. Export propensity, export intensity and performance: the role of the entrepreneurial team. Journal of International Business Studies, v.43, n.8, p. 693$718,2012$.

GENÇTÜRK, E.F.; KOTABE, M. The effect of export assistance program usage on export performance: a contingency explanation. Journal of International Marketing, v.9, n.2, p.51-71, 2001.

GIL-BARRAGAN, J.M.; PALACIOS-CHACON, L.A. Export Intensity of SMEs from emerging markets: a configurational analysis. Journal of Ecomomics ans Economic Education Research, v.19, n.3, p.1-15, 2018.

GJEKANOVIKJ, A.; BIZMPIROULAS, A.; ROTSIOS, K. Export Success Factors for Table Olives: The Perception of Greek Exporting Firms. Procedia Economic and Finance, v.33, n.1, p.584-594, 2015.

GLAVAS, C.; MATHEWS, S. How international entrepreneurship characteristics influence Internet capabilities for the international business processes of the firm. International Business Review, v.23, n.1, p. 228-245, 2014.

GUNARATNE, K.A. Exporting to internationalise: only a small percentage of emerging SMEs from developing countries succeed when a large majority fail. Management Studies, v. 2, n.7, p. 427-446, 2014. 
LEE, H.; KELLEY, D.; LEE, J.; LEE, S. SME survival: the impact of internationalization, technology resources, and alliances. Journal of Small Business Management. v. 50, n. 1, p. $1-19,2012$.

LEONIDOU, L. C.; KATSIKEAS, C. S.; PALIHAWADANA, D.; SPYROPOULOU, S.A. An analytical review of the factors stimulating smaller firms to export: Implications for policy-makers. International Marketing Review, v.24, n.6, p. 735-770, 2007.

LEONIDOU, L. C.; PALIHAWADANA, D.; THEODOSIOU, M. National Export-Promotion Programs as Drivers of Organizational Resources and Capabilities: Effects on Strategy, Competitive Advantage and Performance. Journal of International Marketing, v. 19, n. 2, p. 129, 2011.

LOVE, J.; ROPER, S. SME innovation, exporting and growth: a review of existing evidence. International Small Business Journal, v. 1, p. 28-48, 2015.

LU, J.W., BEAMISH, P.W. The internationalization and performance of SMEs. Strategic Management Journal, v. 22, n. 6-7, p. 565-586, 2001.

MACHADO, M.A.; NIQUE, W. M.; FEHSE, F.B. Orientação Internacional e comprometimento exportador na rápida Internacionalização de pequenas e médias empresas: validação de escalas e implicações para o caso brasileiro. Revista de Administração (São Paulo), v.5, n.3, p. 255-265, 2016.

MANSFIELD, E.D.; REINHARDT E. International institutions and the volatility of international trade. International Organization, v.62, n.4 p. 621-652, 2008.

MDIC, Ministério da Indústria, Comércio Exterior e Serviços. Sítio < http://www.mdic.gov.br/ /comercio-exterior/pnce > Acesso em 01 de março de 2019.

MELLO, Myriam M.S. Avaliação das mulheres agricultoras sobre os efeitos do PRONAF em suas condições de vida. Dissertação (mestrado), Universidade Federal de Viçosa, 2017.

MESCHI, P.; RICARD, A.; MOORE, E.T. Fast and furious or slow and cautious? The joint impact of age at internationalization, speed, and risk diversity on the survival of exporting firms. Journal of International Management, v.23, n.3, p. 279-291, 2017.

MOEN, Ø.; HEGGESETH, A. G.; LOME, O. The Positive Effect of Motivation and International Orientation on SME Growth. Journal of Small Business Management, v.54, n.2, p. 659-678, 2016.

MORAIS, F.; FERREIRA, J.J. SME internationalisation process: key issues and contributions, existing gaps and the future research agenda. European Management Journal, v. 38, n.1, p. 62-77, 2020.

NARAYANAN, V. Export Barriers for Small and Medium-sized Enterprises: A Literature Review based on Leonidou's Model. Entrepreneurial Business and Economics Review, v.3, n.2, p.105-123, 2015.

NAVARRO-GARCIA, A.; REY-MORENO, M.; BARRERA-BARRERA, R. Compromiso, recursos, emprendimiento exportador y resultados empresariales. Revista de Administração de Empresas/FGV-EAESP, v.57, n.2, p. 135-147, 2017.

OMC, Organização Mundial do Comércio. World Trade Organization Statistical Review 2019. 2019. Disponível em https://www.wto.org/english/res_e/statis_e/wts2019_e/wts2019. Acesso em 20 de junho de 2019.

PAUL, J.; PARTHASARATHY, S.; GUPTA, P. Exporting challenges of SMEs: A review and future research agenda. Journal of World Business, v.52, n.1, p. 327-342, 2017. 
RAGIN, C.C. Redesigning Social Inquiry - Fuzzy Sets and Beyond. University of Chicago Press, 2008.

RIHOUX, B.; RAGIN, C.C. Configurational comparative methods. Thousand Oaks: Sage Publications, Inc., 2009.

SANDES-FREITAS, V.; BIZZARRO-NETO, F. Qualitative Comparative Analysis (QCA): usos e aplicações do método. Revista Política Hoje, v.24, n.2, p. 103-117, 2015.

SEBRAE, Serviço Brasileiro de Apoio às Micro e Pequenas Empresas. Sítio: www.sebrae.com.br, Acesso em 20 de setembro de 2018.

STOIAN, M.C.; RIALP, A.; RIALP, J. Export performance under the microscope: A glance through Spanish lenses. International Business Review, v. 20, n.1, 2011.

SULLIVAN, D.; BAUERSCHMIDT, A. Incremental Internationalization: A Test of Johnson and Vahlne's Thesis. Management International Review, v.30, n.1, p.19-30, 1990.

TAN, A.; BREWERB, P.; LIESCH, P. Rigitidy in SME export commencement decisions. International Business Review, v. 27, n.1, p. 46-55, 2018.

TANG, F. Knowledge transfer in intra-organization networks. Systems Research and Behavioral Science, v.28, n.3, p. 270-282, 2011.

TRIMECHE, M.B.B. Export problems and stimuli associated with performance in the Arab market context: insights from the Japanese. Journal of Transnational Management Development, v. 8, n. 1/2, p. 53-81, 2002.

VAILLANT, Y.; LAFUENTE, E.; BAYON, M.C. Early internationalization patterns and export market persistence: a pseudo-panel data analysis. Small Business Economy, 2018. https://doi.org/10.1007/s11187-018-0071-z.

WILLIAMS, D.A. Export stimulation of micro-and small locally owned firms from emerging environments: New evidence. Journal of International Entrepreneurship, v. 6, n.3, p. 101$122,2008$. 